\title{
Recent advances in the climate change biology literature: describing the whole elephant
}

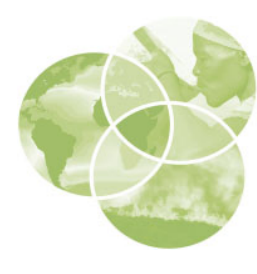

\author{
A. Townsend Peterson, ${ }^{1 *}$ Shaily Menon ${ }^{2}$ and Xingong $\mathrm{Li}^{3}$
}

\begin{abstract}
Climate change biology is seeing a wave of new contributions, which are reviewed herein. Contributions treat shifts in phenology and distribution, and both document past and forecast future effects. However, many of the current wave of contributions are observational and correlational, and few are experimental in nature, and too often a conceptual framework in which to contextualize the results is lacking. An additional gap is the lack of effective cross-linking among areas of research, for example, connection of sea-level rise and climate change implications for distributions of species, or evolutionary adaptation studies with distributional shift studies. Although numerous important contributions have emerged in recent years, synthesis of this phenomenon and its consequences has not yet been achieved. (c) 2010 John Wiley \& Sons, Ltd. WIREs Clim Change
\end{abstract}

$I^{n}$ $n$ the celebrated story of an elephant being described by blind men, adapted from an Indian fable by the poet John Godfrey Saxe (1816-1887), six men attempt to comprehend an elephant, but each describes the part that is nearest to him. One touches its trunk, another its tusk, another its tail, and so on, each deducing the elephant's shape from the part that he has touched. Scientists fall into this same trap: they become engrossed in particular lines of research, and yet miss swaths of the burgeoning literature or miss putting together pieces that might shed better light on the overall whole. In this way, each of us becomes a scientific blind man trying to describe an elephant. The question that we address in this review is akin to the one that those six men faced: how much information has the scientific world accumulated that could help us to comprehend the broader picture of climate change biology?

Climate change is increasingly the subject of research attention from scientists concerned about its likely impacts. Literature related to climate change is being published at prolific rates, so as to make

\footnotetext{
*Correspondence to: town@ku.edu

${ }^{1}$ Biodiversity Institute, The University of Kansas, Lawrence, KS 66044, USA

${ }^{2}$ Department of Biology, Grand Valley State University, Allendale, MI 49401, USA

${ }^{3}$ Department of Geography, The University of Kansas, Lawrence, KS 66044, USA

DOI: $10.1002 / \mathrm{wcc} .59$
}

us all susceptible to misdescribing the elephant. By some reports, the number of climate change biology publications is doubling every 11 years and approached 10,000 by the year $2000 .{ }^{1}$ Periodic reviews of current literature, such as this one, serve to rescue from this syndrome those who, like the authors of this review, do not always stay on top of the literature as much as we might wish. The aim of this review is to catch up on climate change biology literature published in the last 3 years.

We assessed the climate change literature from 2007 to 2009 in considerable detail, with diverse searches over several search engines. After assembling a first suite of publications that we regarded as potentially important, we read through all, sorted them into functional categories, and discarded more minor contributions. We divided contributions into documentation of changes in phenology and geographic distributions and then explored exercises in forecasting effects of climate on species directly, as well as indirectly via sea level rise and marine intrusion. Finally, we reviewed efforts toward incorporation of climate change considerations into biodiversity conservation efforts. The result is a view of the recent climate change literature that is somewhat eclectic, focusing in particular on organismal dimensions of climate change implications for biology and reviewing in somewhat less detail the burgeoning literature on ecosystem-level implications. Nonetheless, we hope that it will be useful in providing an overview 
of recent activity and findings in climate change biology.

\section{PHENOLOGY CHANGES}

Considerable evidence is accumulating to indicate that the seasonal phenology of diverse organisms is changing, mainly in response to shorter winters and earlier springs. The evidence is without exception consistent with climate change expectations (e.g., no evidence is presented for shifts to later spring initiation of activity). However, as will be appreciated in the more detailed treatment below, the picture is not without considerable complexity.

Two exemplary studies have examined general landscape-level shifts in seasonality and vegetation phenology. Julien and Sobrino ${ }^{2}$ examined normalized difference vegetation index greenup and browndown timing over 1981-2003. Their analyses indicated an advance of spring greenup globally by 0.38 days/year and a delay of browndown by 0.45 days/year. Over the more restricted area of boreal Eurasia, Delbart et $\mathrm{al}^{3}{ }^{3}$ used a combination of remote sensing and observational data sources to extend the comparisons back to the 1920s-they found both region-to-region variation and temporal variation across decades, although the present advance in greenup timing is almost universal across Eurasia. In sum, then, global and regional trends are consistently toward earlier springs and later falls, with consequently longer growing seasons each year.

On more local scales, a rich literature is emerging, particularly as regards plant phenology. For example, Miller-Rushing and Primack ${ }^{4}$ used a novel long-term data set originated by Henry David Thoreau in 1852 to measure phenological changes in $>500$ plant taxa in Massachusetts and showed an overall change of $\sim 7$ days in greenup dates, but considerable variation among taxa and functional groups of plants. In a more comparative vein, Vitasse et al. ${ }^{5}$ used 3 years' data across 41 populations of four tree species over $1500 \mathrm{~m}$ of elevation in southern France to estimate advances of 1.9-6.6 days $/{ }^{\circ} \mathrm{C}$ for greenup and delays of $0.0-5.6$ days $/{ }^{\circ} \mathrm{C}$ for browndown. Finally, Inouye ${ }^{6}$ showed both advancing greenup and emergence in montane wildflowers, but a serious fitness cost of earlier greenup incurred by frost damage, and Meis et al. ${ }^{7}$ showed a 1.6 day/year advance of spring chlorophyll blooms in aquatic systems, but linked the advance to temperature increases rather than to changes in ice cover. Overall, the complexity in the details of phenological responses in plants appears to be considerable.
The other taxon for which phenological information relevant to climate change has been abundant is birds, given the legions of observers and data gatherers. For example, taking advantage of a novel 46-year data set for bird migration in eastern North America, Buskirk et al. ${ }^{8}$ showed earlier Spring arrival times, but no overall change in Autumn return dates, again with considerable variation among species in magnitude of effects. A 23-year data set from central North America showed short-distance migrants responding more acutely to temperature variation than long-distance migrants, but again considerable complexity and variation was the dominant theme. ${ }^{9}$ Finally, Møller et al. ${ }^{10}$ demonstrated that European migratory bird species not showing phenological responses tended to be those species that are presently in population declines.

Experimental studies offer additional functional detail and considerably improved inferential power over correlational approaches. For example, Post et al. ${ }^{11}$ used experimental manipulations of warming on life histories of three alpine plant species to isolate causative factors, finding considerable variation among species' responses. Taylor et al. ${ }^{12}$ and Wipf et al. ${ }^{13}$ both used detailed experimental approaches to confirm effects of particular factors (e.g., $\mathrm{CO}_{2}$ concentration, snow depth, timing of snowmelt) and parse effects of rising atmospheric $\mathrm{CO}_{2}$ concentrations and frost events from temperature effects, respectively. Similarly, Visser et al. ${ }^{14}$ used experimental temperature manipulations to show direct temperature effect, independent of food availability, in timing of reproduction in European tits (Parus major). Finally, van Asch et al. ${ }^{15}$ offered a distinct perspective, using detailed studies of heritability and genetic correlations to reflect on the evolutionary potential of a moth (Operophtera brumata), showing ample potential for evolutionary adaptation to restore herbivore-plant synchrony in the face of changing climatic conditions, and adding a useful evolutionary perspective on these questions; work by Jump et al. ${ }^{16}$ has yielded similar conclusions of ample evolutionary potential for adaptive response in a Mediterranean shrub. Such incisive studies of complex evolutionary and ecological phenomena will be key in elucidating likely future dynamics of species in changing climates. ${ }^{17,18}$

\section{POPULATION AND DISTRIBUTION CHANGES}

A body of evidence is accumulating that shows manifold populational and distributional trends that are at least correlated with and attributed to climate change effects. The vast majority of this accumulating 
evidence is coincident with general expectations of effects of warming climates, and particular studies have found associations that appear causal. However, these range effects may well be only the tip of the iceberg that happens to be visible; some studies cited below are suggestive of much more dramatic effects soon to be manifested.

Examples of the sorts of populational and distributional changes being documented include the following. Whitfield et al. ${ }^{19}$ documented dramatic population declines in terrestrial amphibians and reptiles at La Selva Biological Station, in Costa Rica, which they link to reduced quantity of forest-floor leaf litter, a critical microhabitat in that ecosystem. Similarly, Chen et al. ${ }^{20}$ showed elevational increases of $67 \mathrm{~m}$ over 42 years along a 1800-m elevational transect on Mount Kinabalu in Borneo, and Seimon et al. ${ }^{21}$ found significant new high-elevation records of amphibians in the Peruvian Andes, as well as records of the fungal pathogen Batrachochytrium dendrobatidis, which bodes ill for high-elevation amphibian populations. In what is perhaps the bestdocumented suite of studies in this vein, the early biodiversity surveys at key sites in California in 1908-1930 by the Museum of Vertebrate Zoology of the University of California at Berkeley were repeated for both birds and mammals and a very detailed documentation of range dynamics was obtained: upward shifts of $\sim 500 \mathrm{~m}$ in half of the mammal species, ranges contracting and expanding, and clear evidence of climatic niche tracking. ${ }^{22,23}$ Visser et al. ${ }^{24}$ showed significant decreases in migratory distances in half of 24 bird species examined between 1932 and 2004 , based on banding information.

An emerging suite of studies offers a complementary viewpoint, focusing on the importance of spatial scale in likely climate change effects on species. Recent work by Trivedi et al. ${ }^{25}$ has compared coarseand fine-resolution estimates of climate change effects on species and has noted that the coarse-resolution view typically overestimates the strength of effects; similar studies by Ashcroft et al. ${ }^{26}$ similarly indicate that coarse-resolution analyses will frequently miss key factors. This work should offer both a cautionary tale of the effects of possible microrefugia on species' persistence in areas and the potential for a calibration of effects estimated at different spatial resolutions.

Finally, a few studies are going beyond simple documentation of patterns of shift and decline to arrive at mechanistic views of the process. Portner and Knust, ${ }^{27}$ for example, identified thermally limited oxygen delivery as the key constraint on distributional potential in the eelpout (Zoarces viviparus), and Andrushchyshyn et al. ${ }^{28}$ used experimental manipulations to identify specific drivers in ciliate community shifts in the face of changing climate. Peterson and Martínez-Meyer ${ }^{29}$ showed populationlevel shifts in abundance northward in large numbers of North American bird species: although not as yet manifested in range shifts, these northward population swells are expected to be manifested as geographic shifts in coming years, with potentially massive implications for bird distributions and community composition patterns. Changes in disease population biology provide a further mechanism for biotic effects: e.g., the chytrid thermal optimum hypothesis (CTOH) relates climate change-induced temperature increases to spread of the chytridiomycosis-causing $B$. dendrobatidis, which in turn leads to widespread amphibian declines. While the evidence is strong for climatecaused amphibian declines, predictions of the $\mathrm{CTOH}$ remain to be fully supported. ${ }^{30}$

\section{FORECASTS}

The literature on climate change biology has seen numerous speculations and commentaries virtually since the inception of the field. ${ }^{31,32}$ In recent literature, particularly insightful commentaries include Carpenter et al. ${ }^{33}$ regarding the potential broad endangerment of reef-building corals, Vermeij and Roopnarine $^{34}$ on likely broad invasions of the Arctic by marine mollusks, and Rahel and Olden ${ }^{35}$ on aquatic invasive species. Although these commentaries are useful in terms of marshaling research efforts, they do remain general, and not based on specific data or analyses. As a consequence, we focus below on actual analytical approaches to anticipating future climate change biology phenomena.

In general, we discern four types of forecasting exercises emerging in the climate change biology literature. (1) Simplest are scenario-based explorations-for example, Sekercioglu et al. ${ }^{36}$ explored four Millennium Assessment-based scenarios and an intermediate estimate of $2.8^{\circ} \mathrm{C}$ surface warming to arrive at estimates of likely climate change-induced bird extinctions. (2) More detailed, species-specific forecasts can be derived from ecological niche models, which have been applied to climate change questions for some time-recent examples include Peterson, ${ }^{37}$ who estimated likely climate-driven shifts in distributions of malaria vector mosquitoes in Africa and Cheung et al. ${ }^{38}$ who incorporated dispersal considerations into an otherwise simple climatic envelope approach to estimate likely climate change effects on marine biodiversity. (3) An alternative that has not as yet been compared quantitatively and satisfactorily with the niche modeling approaches is that 
of process-based modeling of species' distributions. ${ }^{39}$ Although these first-principles approaches are conceptually attractive, their ability to incorporate the full complexity of distributional phenomena has not been established firmly enough (but see excellent explorations by Porter et al. ${ }^{40}$ ) Finally, (4) a conceptually quite distinct approach is that of dynamic vegetation modeling, which integrates Earth system processes to develop ecosystem-level forecasts. ${ }^{41}$ Although each of these four forecasting approaches has strengths, we see little integration among them; important steps forward have included incorporation of processes of dispersal, demography, and disturbance in the niche modeling framework, ${ }^{42}$ although much development and exploration remains ahead.

A growing number of studies has now gone beyond simple development of forecasts to test and corroborate model predictions. For example, Gregory et al. ${ }^{43}$ showed significant relationships between areal trends predicted by niche models and actual population declines over 1980-2005 in European bird populations; Kharouba et al. ${ }^{44}$ developed similar corroborative tests for Canadian butterfly populations. On broader temporal scales, Guralnick $^{45,46}$ tested a previous hypothesis about relative effects of climate change on flatlands versus montane species by means of comparisons of present-day and Late Pleistocene distributional areas. Probably, the clearest test is that of Foden et al. ${ }^{47}$ who used broad surveys of mortality in a South African tree to test predictions of niche models, finding significant and clear predictivity regarding population trends and range retraction patterns predicted from niche models.

Given sufficient and appropriate corroboration of climate change model predictions for biodiversity, genuine forecasts can be assembled. For example, Carroll et al. ${ }^{48}$ explored the possibility of reintroductions of two regionally extinct butterfly species into Great Britain, based on ecological niche model projections. In an application akin to niche modeling, Schlenker and Roberts ${ }^{49}$ used very detailed data on crop yields for several crop plants to infer likely trends in productivity across the United States. These actual forecasts integrate known and assumed causal linkages with modeled future climatic shifts to make an educated guess at future situations.

What is emerging-if not since our blind scientists began touching the elephant, at least over the past decade of climate change biology research-is a suite of general principles that appear to guide or constrain biological responses to warming climates. The obvious ones have been known for a long time: species' activity will shift to initiate earlier and terminate later in the year, and geographic distributions should shift poleward in latitude and upward in elevation when relief is available; these ideas have seen abundant support in the studies reviewed above and others. Certainly, species in bounded systems will confront particular problems (e.g., islands, or mountain ranges, rivers, deserts, or other barriers that run east to west). More recently, the suggestion has been made that species distributed in flatlands areas will see more dramatic horizontal shifts of their habitable areas than species distributed in montane areas, ${ }^{50}$ which has now seen support from subsequent studies. ${ }^{45,46}$ Finally, a broad consensus is emerging that species' responses to changing climates are highly idiosyncratic and do not follow clear or consistent patterns, even in the case of (currently) co-distributed species.

\section{SEA LEVEL RISE/MARINE INTRUSION}

A dimension of climate change biology that has been relatively much less well explored is that of sea level rise and its consequent effects on species and ecosystems. To our knowledge, no studies have as yet addressed this phenomenon in relation to elements of marine biodiversity, although estuarine and terrestrial systems are beginning to see attention (see overview in Ref 51). An important step forward was the improvement in techniques for identifying areas of inundation over broad regions, based on scenarios of sea level rise and digital elevation models of coastal areas. $^{52}$

The work done on sea-level rise implications for biological systems has focused mostly at the level of ecosystems. Retrospective analyses have analyzed ecosystem health in relation to sea level and identified key factors in loss or gain of area. ${ }^{53,54}$ Prospective analyses have depended on models of ecosystem growth and decline, ${ }^{55,56}$ but have been limited to local areas only, resulting in a proposal for broader-area monitoring networks for tracking these phenomena. ${ }^{57}$ Factors implicated as critical have been varied, from individual species' tolerances and interactions with drought ${ }^{58}$ to human management regimes. ${ }^{59}$ Mangrove systems, located at the land-sea interface, have seen most attention and appear to be particularly vulnerable. ${ }^{60,61}$ Finally, a few experimental manipulations have been developed (e.g., Ref ${ }^{62}$ ), which have emphasized species-level tolerances in determining responses to sea level rise.

What is missing, nonetheless, is a more comprehensive view of sea-level rise implications for biodiversity. Only one study has taken a broaderscope view of these implications. ${ }^{63}$ Much more indepth exploration of sea-level rise implications for 
terrestrial and marine systems is needed, linking detailed biodiversity information with scenarios of marine intrusion (or extension, in the case of marine systems). At the moment, this gap is a significant failing in the climate change biology literature.

\section{CONSERVATION}

As with the question of forecasting, general discussions of likely conservation challenges abound in the climate change literature. Recent reviews include those of Galatowitsch et al. ${ }^{64}$ on conservation futures in the central portion of North America and Mawdsley et al. ${ }^{65}$ and Heller and Zavaleta ${ }^{66}$ on climate change adaptation strategies that have been proposed for conservation initiatives. Once again, however, we prefer to see conservation planning based on actual forecasts rather than generalities. If nothing else, this preference is predicated on the perpetual emergence of naysayers: for instance, Hodgson et al. ${ }^{67}$ argue that connectivity and future sustainability are less important than present habitat area and quality, even though presentday habitat area and quality may mean little as species' ranges reorganize and shift dramatically, the reality of which should be clear from the studies reviewed above.

Coetzee et al. ${ }^{68}$ demonstrated the reality of one of those initial speculations-that present-day conservation planning and protected area networks will likely become less effective over coming decades. This sort of situation, we suspect, will become quite common in the coming decades. Further challenges for conservation planning in changing climates were pointed out by Grivet et al. ${ }^{69}$, who emphasized the need for inclusion of spatial genetic structure of species, beyond simple representation of species in protected area networks. Initial examples of how present-day conservation networks can be adapted to be 'climate change proof' are now being developed, as exemplified by the analyses of Vos et al. ${ }^{70}$ over northwestern Europe. However, as pointed out by Hannah et al., ${ }^{71}$ remediation steps taken earlier in the process of climate change will be more effective and less costly; still, they found that none of the strategies explored avoided climate change-caused losses completely.

A comprehensive conceptual framework for such adaptation-based strategies has still been lacking in large part in this work. Moffett and Sarkar ${ }^{72}$ presented an extremely promising analytical framework, termed multicriteria decision-making methods, within which distinct suites of factors can be incorporated, assigned different weights, and considered at distinct points in time. This sort of multifactorial approach offers considerable promise for development of truly integrative conservation planning exercises.

\section{CONCLUSIONS}

This article reviews a swath of literature concerning climate change biology that has appeared in the past 2-3 years. Many of the studies that we have reviewed emphasize the fundamental value of long-term and legacy data sets-in one case going back even to Henry David Thoreau in the middle 19th century. ${ }^{4}$ Climate change being a relatively slow process, its emergence as a global change phenomenon has placed a premium on long-term, longitudinal data sets that can speak to climate change influences on biodiversity and biology. Still more generally, climate change biology demands broad-scale points of view which underline the need for open sharing of biodiversity data ${ }^{73}$ to make such analyses even possible.

Although much research activity has emerged and been published in recent years, we still see little if any work that can be termed genuinely comprehensive. Climate change biology covers aspects of genetics and evolutionary potential, phenology and seasonality, range and dispersal corridors, and interactions among species, and thus includes considerable complexity. We see need for better documentation of climate change effects on biodiversity, in terms of observations and experiments, but these documentary studies should be developed within explicit conceptual frameworks. Better forecasts are also necessary, with broader exploration of forecasting applications, more robust methods used, and more tests of predictions to make the forecasts more realistic and believable. More generally, we urge climate change biologists to place their studies within a broader overall perspective, in which climate change affects individual physiology, which maps onto population change, which in turn translates into phenological changes and geographic range shifts. The end result of these changes and shifts is genuine community turnover and biotic change, as has been anticipated since the earliest commentaries ${ }^{31,32}$ and climate change forecasting exercises.

So, temporarily rescued from misdescribing the elephant, we are pleased to see that the climate change biology community has made significant progress with documenting and tracking the emergence of climate change effects on species, basically confirming the reality of this phenomenon. However, in spite of significant advance along several lines of investigation, we see relatively little in the way of cross-linking among those areas, and so the field remains somewhat 
'stovepiped', and thus vulnerable to describing the overall climate change elephant incorrectly. Our view is that the field has not advanced qualitatively toward a broader conceptual foundation or more synthetic methodologies that could sustain its development over coming decades.

\section{REFERENCES}

1. Stanhill G. The growth of climate change science: a scientometric study. Clim Change 2001, 48:515-524.

2. Julien Y, Sobrino JA. Global land surface phenology trends from GIMMS database. Int J Remote Sens 2009, 30:3495-3513.

3. Delbart N, Picard G, Toan TL, Kergoat L, Quegan S, Woodward I, Dye D, Fedotova V. Spring phenology in boreal Eurasia over a nearly century time scale. Glob Change Biol 2008, 14:603-614.

4. Miller-Rushing AJ, Primack RB. Global warming and flowering times in Thoreau's Concord: A community perspective. Ecology 2008, 89:332-341.

5. Vitasse Y, Porté A, Kremer A, Michalet R, Delzon S. Responses of canopy duration to temperature changes in four temperate tree species: Relative contributions of spring and autumn leaf phenology. Oecologia 2009, 161:187-198.

6. Inouye DW. Effects of climate change on phenology, frost damage, and floral abundance of montane wildflowers. Ecology 2008, 89:353-362.

7. Meis S, Thackeray SJ, Jones ID. Effects of recent climate change on phytoplankton phenology in a temperate lake. Freshw Biol 2009, 54:1888-1898.

8. Buskirk JV, Mulvihill RS, Leberman RC. Variable shifts in spring and autumn migration phenology in North American songbirds associated with climate change. Glob Change Biol 2009, 15:760-771.

9. MacMynowski D, Root T. Climate and the complexity of migratory phenology: sexes, migratory distance, and arrival distributions. Int J Biometeorol 2007, 51:361-373.

10. Møller AP, Rubolini D, Lehikoinen E. Populations of migratory bird species that did not show a phenological response to climate change are declining. Proc Natl Acad Sci U S A 2008, 105:16195-16200.

11. Post ES, Pedersen C, Wilmers CC, Forchhammer MC. Phenological sequences reveal aggregate life history response to climatic warming. Ecology 2008, $89: 363-370$.

12. Taylor G, Tallis MJ, Giardina CP, Percy KE, Miglietta F, Gupta PS, Gioli B, Calfapietra C, Gielen B, Kubiske ME, et al.. Future atmospheric $\mathrm{CO}_{2}$ leads to delayed autumnal senescence. Glob Change Biol 2008, $14: 264-275$.
13. Wipf S, Stoeckli V, Bebi P. Winter climate change in alpine tundra: plant responses to changes in snow depth and snowmelt timing. Clim Change 2009, 94:105-121.

14. Visser ME, Holleman LJM, Caro SP. Temperature has a causal effect on avian timing of reproduction. Proc $R$ Soc B 2009, 276:2323-2331.

15. van Asch M, vanTienderen PH, Holleman LJM, Visser ME. Predicting adaptation of phenology in response to climate change, an insect herbivore example. Glob Change Biol 2007, 13:1596-1604.

16. Jump AS, Peñuelas J, Rico L, Ramallo E, Estiarte M, Martínez-Izquierdo J, Lloret F. Simulated climate change provokes rapid genetic change in the Mediterranean shrub Fumana thymifolia. Glob Change Biol 2008, 14:637-643.

17. Visser ME. Keeping up with a warming world; assessing the rate of adaptation to climate change. Proc $R$ Soc B 2008, 275:649-659.

18. Smith TB, Bernatchez L. Evolutionary change in human-altered environments, Mol Ecol 2008, 17:1-8.

19. Whitfield SM, Bell KE, Philippi T, Sasa M, Bolaños F, Chaves G, Savage JM, Donnelly MA. Amphibian and reptile declines over 35 years at La Selva, Costa Rica. Proc Natl Acad Sci U S A 2007, 104:8352-8356.

20. Chen I-C, Shiu H-J, Benedick S, Holloway JD, Chey VK, Barlow HS, Hill JK, Thomas CD. Elevation increases in moth assemblages over 42 years on a tropical mountain. Proc Natl Acad Sci U S A 2009, 106:1479-1483.

21. Seimon TA, Seimon A, Daszak P, Halloy SRP, Schloegel LM, Aguilar C, Sar A, Sowell P, Hyatt AD, Konecky, et al. Upward range extension of Andean anurans and chytridiomycosis to extreme elevations in response to tropical deglaciation. Glob Change Biol 2007, 13:288-299.

22. Moritz C, Patton JL, Conroy CJ, Parra JL, White GC, Beissinger SR. Impact of a century of climate change on small-mammal communities in Yosemite National Park, USA. Science 2008, 322:261-264.

23. Tingley MW, Monahan WB, Beissinger SR, Moritz C. Birds track their Grinnellian niche through a century of climate change. Proc Natl Acad Sci U S A 2009, 106:19637-19643.

24. Visser ME, Perdeck AC, Balen JHv, Both C. Climate change leads to decreasing bird migration distances. Glob Change Biol 2009, 15:1859-1865. 
25. Trivedi MR, Berry PM, Morecroft MD, Dawson TP. Spatial scale affects bioclimate model projections of climate change impacts on mountain plants. Glob Change Biol 2008, 14:1089-1103.

26. Ashcroft MB, Chisholm LA, French KO. Climate change at the landscape scale: predicting fine-grained spatial heterogeneity in warming and potential refugia for vegetation. Glob Change Biol 2009, 15:656-667.

27. Portner HO, Knust R. Climate change affects marine fishes through the oxygen limitation of thermal tolerance. Science 2007, 315:95-97.

28. Andrushchyshyn OP, Wilson KP, Williams DD. Climate change-predicted shifts in the temperature regime of shallow groundwater produce rapid responses in ciliate communities. Glob Change Biol 2009, $15: 2518-2538$.

29. Peterson AT, Martínez-Meyer E. Pervasive poleward shifts among North American bird species. Biodiversity 2009, 9:14-16.

30. Kilpatrick AM, Briggs CJ, Daszak P. The ecology and impact of chytridiomycosis: an emerging disease of amphibians. TREE 2010, 25:109-118.

31. Peters RL, Darling JDS. The greenhouse effect and nature reserves. Bioscience 1985, 35:707-717.

32. Dobson A, Jolly A, Rubenstein D. The greenhouse effect and biological diversity. Trends Ecol Evol 1989, $4: 64-68$.

33. Carpenter KE, Abrar M, Aeby G, Aronson RB, Banks S, Bruckner A, Chiriboga A, Cortes J, Delbeek JC, DeVantier L, et al. One-third of reef-building corals face elevated extinction risk from climate change and local impacts. Science 2008, 321:560-563.

34. Vermeij GJ, Roopnarine PD. The coming Arctic invasion. Science 2008, 321:780-781.

35. Rahel FJ, Olden JD. Assessing the effects of climate change on aquatic invasive species. Conserv Biol 2008, 22:521-533.

36. Sekercioglu CH, Schneider SH, Fay JP, Loarie SR. Climate change, elevational range shifts, and bird extinctions. Conserv Biol 2008, 22:140-150.

37. Peterson AT. Shifting malaria transmission risk across Africa with warming climates. BMC Infect Dis 2009, 9:5.

38. Cheung WWL, Lam VWY, Sarmiento JL, Kearney K, Watson R, Pauly D. Projecting global marine biodiversity impacts under climate change scenarios. Fish Fish 2009, 10:235-251.

39. Morin X, Augspurger C, Chuine I. Process-based modeling of species' distributions: what limits temperate tree species' range boundaries? Ecology 2007, 88:2280-2291.

40. Porter WP, Sabo JL, Tracy CR, Reichman OJ, Ramankutty N. Physiology on a landscape scale: plant-animal interactions. Integr Comp Biol 2002, 42:431-453.
41. Scheiter S, Higgins SI. Impacts of climate change on the vegetation of Africa: an adaptive dynamic vegetation modelling approach. Glob Change Biol 2009, 15:2224-2246.

42. Keith DA, Akçakaya HR, Thuiller W, Midgley GF, Pearson RG, Phillips SJ, Regan HM, Araújo MB, Rebelo TG. Predicting extinction risks under climate change: coupling stochastic population models with dynamic bioclimatic habitat models. Biol Lett 2008, 4:560-563.

43. Gregory RD, Willis SG, Jiguet F, Voríšek P, Klvanová A, Strien Av, Huntley B, Collingham YC, Couvet D, Green RE. An indicator of the impact of climatic change on European bird populations. PLOS ONE 2009, 4:e4678.

44. Kharouba HM, Algar AC, Kerr JT. Historically calibrated predictions of butterfly species' range shift using global change as a pseudo-experiment. Ecology 2009, 90:2213-2222.

45. Guralnick R. Do flatland- and mountain-dwelling species show different structuring of their experienced environment over latitude? A western vs. centraleastern North America rodent multispecies comparison. Divers Distrib 2006, 12:731-741.

46. Guralnick R. Differential effects of past climate warming on mountain and flatland species distributions: a multispecies North American mammal assessment. Glob Ecol Biogeogr 2007, 16:14-23.

47. Foden W, Midgley GF, Hughes G, Bond WJ, Thuiller W, Hoffman MT, Kaleme P, Underhill LG, Rebelo A, Hannah L. A changing climate is eroding the geographical range of the Namib Desert tree Aloe through population declines and dispersal lags. Divers Distrib 2007, 13:645-653.

48. Carroll MJ, Anderson BJ, Brereton TM, Knight SJ, Kudrna O, Thomas CD. Climate change and translocations: the potential to re-establish two regionallyextinct butterfly species in Britain. Biol Conserv 2009, 142:2114-2121.

49. Schlenker W, Roberts MJ. Nonlinear temperature effects indicate severe damages to U.S. crop yields under climate change. Proc Natl Acad Sci U S A 2009, 106:15594-15598.

50. Peterson AT. Projected climate change effects on Rocky Mountain and Great Plains birds: generalities of biodiversity consequences. Glob Change Biol 2003, 9:647-655.

51. Day J, Christian R, Boesch D, Yáñez-Arancibia A, Morris J, Twilley R, Naylor L, Schaffner L, Stevenson C. Consequences of climate change on the ecogeomorphology of coastal wetlands. Estuaries Coasts 2008, 31:477-491.

52. Li X, Rowley RJ, Kostelnick JC, Braaten D, Meisel J, Hulbutta K. GIS analysis of global inundation impacts from sea level rise. Photogramm Eng Remote Sens 2009, 75:807-818. 
53. Kirwan ML, Kirwan JL, Copenheaver CA. Dynamics of an estuarine forest and its response to rising sea level. J Coast Res 2009, 23:457-463.

54 Virah-Sawmy M, Willis KJ, Gillson L. Threshold response of Madagascar's littoral forest to sea-level rise. Glob Ecol Biogeogr 2009, 18:98-110.

55. Kirwan ML, Murray AB. Ecological and morphological response of brackish tidal marshland to the next century of sea level rise: Westham Island, British Columbia. Glob Planet Change 2007, 60:471-486.

56. Craft C, Clough J, Ehman J, Joye S, Park R, Pennings S, Guo H, Machmuller M. Forecasting the effects of accelerated sea-level rise on tidal marsh ecosystem services. Front Ecol Environ 2009, 7:73-78.

57. Hopkinson CS, Lugo AE, Alber M, Covich AP, Van Bloem SJ. Forecasting effects of sea-level rise and windstorms on coastal and inland ecosystems. Front Ecol Environ 2008, 6:255-263.

58. Desantis LRG, Bhotika S, Williams K, Putz FE. Sea-level rise and drought interactions accelerate forest decline on the Gulf Coast of Florida, USA. Glob Change Biol 2007, 13:2349-2360.

59. Richards J, Mokrech M, Berry P, Nicholls R. Regional assessment of climate change impacts on coastal and fluvial ecosystems and the scope for adaptation. Clim Change 2008, 90:141-167.

60. Gilman E, Ellison J, Coleman R. Assessment of mangrove response to projected relative sea-level rise and recent historical reconstruction of shoreline position. Environ Monit Assess 2007, 124:105-130.

61. Jagtap TG, Nagle VL. Response and adaptability of mangrove habitats from the Indian Subcontinent to changing climate. AMBIO 2007, 36:328-334.

62. Spalding E, Hester M. Interactive effects of hydrology and salinity on oligohaline plant species productivity: Implications of relative sea-level rise. Estuaries Coasts 2007, 30:214-225.

63. Menon S, Soberón J, Li X, Peterson AT. Preliminary global assessment of terrestrial biodiversity consequences of sea-level rise mediated by climate change. Biod and Conserv 2010, 19:1599-1609.
64. Galatowitsch S, Frelich L, Phillips-Mao L. Regional climate change adaptation strategies for biodiversity conservation in a midcontinental region of North America. Biol Conserv 2009, 142:2012-2022.

65. Mawdsley JR, O’Malley R, Ojima DS. A review of climate-change adaptation strategies for wildlife management and biodiversity conservation. Conserv Biol 2009, 23:1080-1089.

66. Heller NE, Zavaleta ES. Biodiversity management in the face of climate change: a review of 22 years of recommendations. Biol Conserv 2009, 142: 14-32.

67. Hodgson JA, Thomas CD, Wintle BA, Moilanen A. Climate change, connectivity and conservation decision making: back to basics. J Appl Ecol 2009, 46:964-969.

68. Coetzee BWT, Robertson MP, Erasmus BFN, Rensburg BJv, Thuiller W. Ensemble models predict Important Bird Areas in southern Africa will become less effective for conserving endemic birds under climate change. Glob Ecol Biogeogr 2009, 18:701-710.

69. Grivet D, Sork VL, Westfall RD, Davis FW. Conserving the evolutionary potential of California valley oak (Quercus lobata Nee): a multivariate genetic approach to conservation planning. Mol Ecol 2008, 17:139-156.

70. Vos CC, Berry P, Opdam P, Baveco H, Nijhof B, O’Hanley J, Bell C, Kuipers H. Adapting landscapes to climate change: examples of climate-proof ecosystem networks and priority adaptation zones. J Appl Ecol 2008, 45:1722-1731.

71. Hannah L, Midgley G, Andelman S, Araújo M, Hughes G, Martinez-Meyer E, Pearson R, Williams P. Protected area needs in a changing climate. Front Ecol Environ 2007, 5:131-138.

72. Moffett A, Sarkar S. Incorporating multiple criteria into the design of conservation area networks: a minireview with recommendations. Divers Distrib 2006, 12:125-137.

73. Edwards JL. Research and societal benefits of the Global Biodiversity Information Facility. Bioscience 2008, 54:486-487. 